\title{
Correlation between serum interleukin- 6 with glomerular filtration rate in systemic lupus erythematosus
}

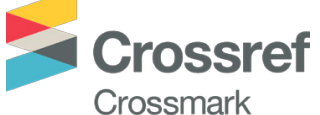

DOI : 10.36216/jpd.v3i1.65

\author{
Gede Kambayana ${ }^{1 *}$, Meryl Pulcheria ${ }^{2}$, I Gde Raka Widiana'
}

\author{
'Department of Internal \\ Medicine,Faculty of Medicine, Udayana \\ University/Sanglah General Hospital, \\ Denpasar, Bali, Indonesia \\ 2Study Programme of Internal \\ Medicine, Udayana University/Sanglah \\ General Hospital, Denpasar, Bali, \\ Indonesia \\ *Korespondensi: \\ Gede Kambayana; Department of \\ Internal Medicine,Faculty of Medicine, \\ Udayana University/Sanglah General \\ Hospital, Denpasar, Bali, Indonesia \\ gde.kembayana@unud.ac.id
}

Diterima: 14 April 2019;

Disetujui: 5 Mei 2019;

Diterbitkan: 25 Mei 2019
Background: Systemic lupus erythematosus (SLE) is characterized by remarkable heterogeneity in clinical manifestations with underlying autoimmune mechanisms. The pleiotropic cytokine interleukin-6 (IL-6) is known to be involved in SLE immunopathogenesis and significantly related to disease activity as well as its complications. Additionally, IL-6 has been demonstrated to underlie important roles in lupus nephritis.

Objective: To determine the correlation between Interleukin 6 (IL-6) serum and glomelular filtration rate (GFR) in SLE. Methods: In this study we investigated the correlation of serum IL- 6 with glomerular filtration rate (GFR) to assess kidney damage in 67 premenopausal patients aged between 17-50 years with inactive SLE. The study variables including age, duration of illness, cumulative corticosteroid dose, MEX-SLEDAI score, serum creatinine, and GFR were obtained through interview and medical record review; whilst serum level of IL-6 was measured using ELISA.

Results: Median level of IL- 6 was found to be $2.71(0.332-10.000) \mathrm{pg} / \mathrm{ml}$. Pearson correlation test showed significant correlation between serum IL-6 and GFR ( $r=0.288, P=0.018)$.

Conclusion: This study result shows that there was positive correlation observed between serum IL- 6 and GFR in inactive SLE.

Keywords: Interleukin-6, Glomerular filtration rate, Systemic lupus erythematosus

\section{BACKGROUND}

Systemic Lupus Eritematosus (SLE) is an autoimmune disease with many variations of clinical manifestation, could affect almost all of the organs and tissues and found on women nine times than men. The prevalence of lupus is estimated around 51 people for every 100,000 people in United States, this number increasing almost three times in the last 40 years. ${ }^{1}$ Indonesia does not have data of the prevalence of SLE that covered the whole region. In 2002, Ciptomangunkusumo Hospital (RSCM) Jakarta recorded $1.4 \%$ of SLE cases from all patients on outpatient visits in the Internal Medical Rheumatology Poly Clinic. ${ }^{2}$ Based on patient data of the rheumatology clinic at Sanglah hospital (RSUP), found 60$70 \%$ of SLE cases of all total visits in 2016.

IL-6 is pleiotropic cytokines that has effects on various organs, not only regulating the immune system and inflammation, but also effecting metabolism and organ development. ${ }^{3,4}$ Some paper said that IL-6 has double effects, at certain levels it has protection effects, but during chronic inflammation condition it mostly become pro inflammation. Under normal circumstances, the acute inflammatory response will induct IL-6, which will stimulate the production of antagonist receptors IL-1, which act as anti-inflammatory mediators. Therefore, IL- 6 could has protection effects. ${ }^{5}$

In SLE, IL-6 is one of inflammatory cytokine that plays a role in the pathogenesis of SLE and correlates with disease activity. IL-6 in SLE will be increased during cardiopulmonary complications, lupus nephritis, neuropsychiatric syndrome and joint damage. ${ }^{6}$ Several studies have shown IL-6 plays significant roles in B-cell hyperactivity and SLE immunopathogenesis and has direct effects on mediating tissue damage and increasing IL-6 levels, it shows a significant correlation with SLE activity $(\mathrm{p}<0.01)$.

In clinical and experimental studies, it was found that IL-6 contributed to kidney damage in glomeluronephritis and other kidney diseases. In a study conducted on mice with lupus nephritis, IL-6 was found to cause fibrosis, tissue damage and many diseases of lupus nephritis. From patient with the Acute Kidney Injury (AKI), it was found that the high levels of IL-6 was a predictive value for increasing patient mortality. ${ }^{8}$

On the other hands several studies conducted by Yael, and friends (2008) showed that IL-6 in AKI patients simultaneously induced an inflammatory response toward damages, but also triggered a trans-signaling mechanism to protect the kidneys from further damage. ${ }^{9}$ The intervention 
study by adding anti-IL- 6 to mice, sepsis performed by Niel and friends (2003), it was shown that IL-6 levels also had anti-inflammatory effects, so high doses of anti-IL-6 in mice with sepsis have fewer benefits compared to the low doses of IL-6 which will be harmful if too much in the blood system, but excessive blockade of IL-6 will increase the risk of death, because IL-6 has an effect to protect the body. ${ }^{10}$

Based on the above studies, to prove the effect of IL-6 on the kidneys in inactive SLE patients, a study of the correlation of IL-6 to GFR was carried out which could later be used as a consideration for giving anti-IL-6 therapy to inactive SLE patients. This study aimed to determine the correlation between IL-6 serum and GFR in SLE.

\section{METHODS}

\section{Study Design and Procedure}

A cross sectional study with 67 samples, aged 17-50 years old, menopause excluded. Sample taking was done on January until March 2018 in Rheumatology Clinic, Internal Medicine, Sanglah Hospital, Denpasar.

Consecutive sampling was done in SLE patients that meet inclusion criteria until the amount needed, then given the education about advantages, objectives, and the risks. If the patient willing to be sample, informed consent was collected. Anamnesis and medical report review conducted to collect datas about age, sick duration, cortcisoteroid cumulation dose, MEX SLEDAI scores, creatinine serum, GFR, and serum IL-6 $5 \mathrm{cc}$ blood sampling was conducted.

Serum IL-6 levels was measured using the Human IL-6 Immunoassay method, with the Quantikine ${ }^{\circledR}$ HS ELISA Kit manufactured by R \& D Systems, Inc. in Minneapolis, United States. The examination results are expressed in numeric form units of $\mathrm{pg} / \mathrm{mL}$. Before the research was carried out, ethically feasible requests were made to the R \& D Unit of the Medical Faculty of Udayana University / Sanglah General Hospital, Denpasar. The researcher then asked for research permission from the Managing Director, RSUP Sanglah and obtained a research permit with number LB.02.01 / IXIV.2.2.1 / 35677/2017, and obtained a letter of Ethics Acceptance from the Education and Training section of Sanglah General Hospital in Denpasar with number: 2235 / UN.14.2 / KEP / 2017.

\section{Statistical Analysis}

Statistical analysis was carried out with the SPSS program. Descriptive analysis used to describe the characteristics of the research subject and the overall research variables. Normally distributed variables with numerical data scales are shown using mean and standard deviation. Not normally distributed ones, displayed using the median and maximum-minimum. Data normality of the analytical method measured by Kolmogorov-Smirnov test. Correlation test is done by Pearson test because both datas are numerical. Both datas are not normally distributed, so data transformation was done by using logistical transformation. After transformation the data are normally distributed, so the correlation tested by the Pearson test.

\section{RESULT}

Based on Table 1, age and GFR data was normally distributed, meanwhile sick duration, corticosteroid doses, MEX-SLEDAI scores, Creatinine, GFR, serum IL-6 datas not normally distributed.

In this study, serum IL-6 levels were not normally distributed with $\mathrm{p}<0.05$ in the Kolmogorov Smirnov test so logistic transformation was carried out. After logistic transformation, the data is normally distributed with a value of $\mathrm{p}>0.05$.

Pearson correlation test between serum IL- 6 and GFR showed positive correlation between serum IL-6 and GFR with $\mathrm{r}=0.288$ and $\mathrm{p}=0.018$ (Table 2). Correlation as shown in scatter plot (Picture 1).

Table 1. Subject Characteristic

\begin{tabular}{lccc}
\multicolumn{1}{c}{ Characteristic } & Mean (s.d) & CI 95\% & Median (min-max) \\
\hline Age (years) & $30.99(8.7)$ & $28.86-33.11$ & $24.00(1-120)$ \\
Sick Duration (Months) & & & $9.00(1.00-40.00)$ \\
Corticosteroid Doses (Grams) & & & $0(0-7)$ \\
MEX-SLEDAI & & & $0.67(0.41-1.76)$ \\
Creatinine (mg/dL) & & $96.53-112.2$ & \\
GFR & $104.37(32.12)$ & & $2.71(0.332-10.000)$ \\
Serum Interleukin 6 (pg/ml) & & &
\end{tabular}

GFR: Glomerular filtration rate 
Table 2 Pearson Correlation Test between Serum Interleukine 6 and Glomerular Filtration Rate

\begin{tabular}{llc}
\hline & & GFR \\
\hline \multirow{2}{*}{ Interleukin 6 serum } & Pearson Correlation & .288 \\
& Sig. (2-tailed) & .018 \\
\hline
\end{tabular}

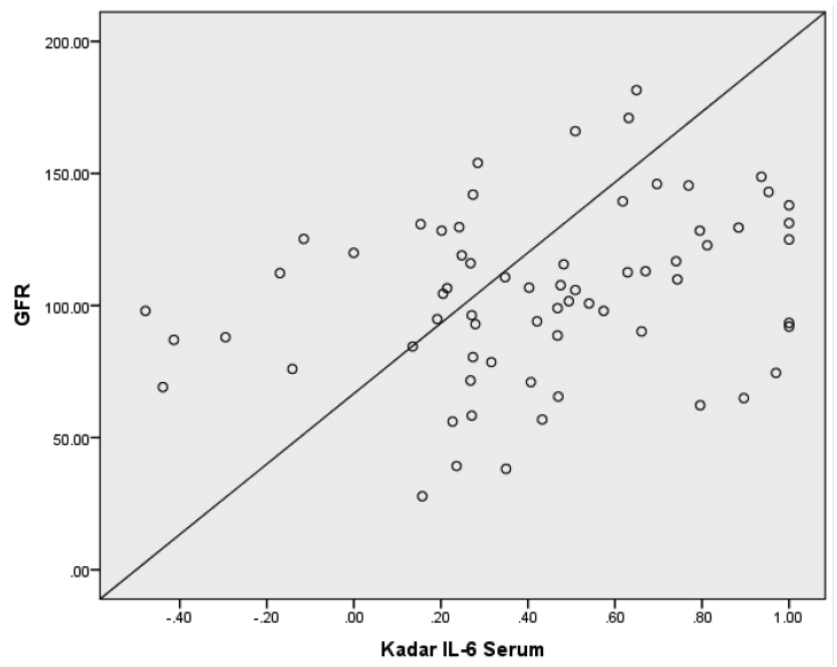

Picture 1 Scatter plot shows positive correlation between serum IL- 6 and GFR ( $r=0.288$ and $p$ 0.018)

\section{DISCUSSION}

This study involved 67 women out patient with SLE at Sanglah Hospital as research subjects. Average subjects age was 30.99 years, almost the same as obtained by Sahar et al. (2015), which is 34.23 years parallel with the peak incidence of SLE (productive age between 15 and 40 years). Studies in Asia Pacific shown the onset age of SLE was 25.7-34.5 years with an average 25.7 years in Malaysia and 26.7 years in Philippines.

Interleukin 6 levels in SLE patients were obtained with median $2.71(0.332-10,000) \mathrm{pg} / \mathrm{ml}$. This result is lower than some previous studies. In the Allesandro et al. (2014) study, mean levels of interleukin 6 were $3.2(2.6-3.9) \mathrm{pg} / \mathrm{ml}$ in SLE patients without treatment, $3.6(2.69-4.31) \mathrm{pg} / \mathrm{ml}$ in SLE patients without renal impairment, and $4(2.64-4.69) \mathrm{pg} /$ $\mathrm{ml}$ in SLE patients with renal impairment. ${ }^{11}$ In the study of Alla, et al (2005), interleukin 6 levels were $135.4 \pm 54.23 \mathrm{pg} /$ $\mathrm{ml}$ in active SLE patients, $47.33 \pm 18.61 \mathrm{pg} / \mathrm{ml}$ in inactive SLE patients and $1.4(0.98-2.28) \mathrm{pg} / \mathrm{ml}$ in the general population. ${ }^{12}$ The Colado study, et al. (2017) involved 200 SLE patients and 196 healthy controls, showed IL-6, IL-10, IL- 12, and IL-17 was higher in SLE patients compared to controls and IL-4 levels were lower in SLE patients than controls. ${ }^{13}$ In Sahar's study, et al. (2015) showed higher IL-6 levels in SLE patients with kidney disorders $(12.12 \mathrm{pg} / \mathrm{ml})$ compared to the normal population with $\mathrm{p}<0.001$, and increased IL-6 levels in SLE patients was positively correlated with lupus nefritis, anemia and SLEDAI score $>4$ with $\mathrm{p}<0.0001$ compared to the control group (history of lupus nephritis). ${ }^{14}$

Most studies shown that interleukin 6 levels are higher in SLE patients than in general population and even higher in active SLE patients, or SLE patients with renal impairment. This study does not compare IL-6 levels between SLE population and general population.

In a case control study conducted by Belinda, et al. (2015), in 201 CKD patients and 201 healthy controls, IL-6 was associated with the prevalence and severity of CKD by comparing the median value of IL-6 in the CKD 2.53 (1.49$4.42) \mathrm{pg} / \mathrm{mL}$ and $1.39(0.95-2.15) \mathrm{pg} / \mathrm{mL}$ in control group with $\mathrm{p}$ value 0.04 . The comparison of IL- 6 in the lowest tertile and highest tertile was obtained with OR 2.5 (95\% CI 1.1 5.5). ${ }^{15}$ Research by Jayanta, et al. (2012) showed that IL-6 levels were higher in participants with low eGFR compared with participants with a higher eGFR. Each increase in eGFR units, correlate with $0.6 \%$ change in IL-6. ${ }^{16}$ Alfons, et al. (2017) found that urine IL-6 levels were associated with glomerulosclerosis and interstitial fibrosis, but not mesangial, extrapilary or endogenous changes in patients with nephropathy $\operatorname{IgA} .{ }^{17}$

In SLE, urine IL-6 levels were significantly correlated with proteiuria $(\mathrm{r}=0.25, \mathrm{p}=0.002)$, and patients with active lupus nephritis correlated with urine IL-6 levels $(r=0.62$, $\mathrm{p}=0.01) .{ }^{18}$ Other studies shows the presence of IL- 6 as an inflammatory cytokine in the kidney. In 19 type III and IV lupus nephritis patients biopsy, immunofluorescence performed using anti-IL-6 monoclonal and 52\% of immunofluorescence showed IL-6 deposits in glomelurus and tubules, shows an important role of IL-6 in lupus nephritis pathogenesis. ${ }^{19}$

Many researches show IL-6 has an important role as proinflammatory cytokine in kidney disorders. IL-6 correlates with the severity of kidney damage and lupus activity. In almost all studies, there is a negative correlation between IL-6 and kidney function. However, this study found a positive correlation, where higher GFR associated with higher IL6. This may be linked with IL-6 role as antiinflammatory cytokine beside its proinflammatory role. Low levels of IL-6 are needed as self-protection in accordance with Yael's research, et al (2008) in AKI and Niel, et al (2003) in sepsis patients. Other reason why this study obtained different result may due to the sample in this study involved patients which is not in the flare up condition. Hence, further study is needed to compare serum IL-6 level within categorized GFR, or compare the serum IL-6 level on patients with kidney disease and control population. 


\section{CONCLUSION}

Positive correlation between serum IL-6 and GFR in SLE patients was observed in this study.

\section{REFERENCES}

1. Bertias G, Cervera R, Boumpas DT. 2012. Systemic Lupus Erythematosus: Pathogenesis and Clinical Feature. EULAR Recommendation.

2. Perhimpunan Rematologi Indonesia. 2011. Diagnosis dan Pengelolaan Lupus Eritematosus Sistemik.

3. Su H, Lei C-T, Zhang C. 2017. Interleukin-6 Signaling Pathway and Its Role in Kidney Diseases: An Update. Front. Immunol;8:405.

4. Tanaka T, Narazaki M, Kishimoto T. 2014. IL-6 in inflammation, Immunity and Diseases. Cold Spring Harb Perspect Biol;6;a016295.

5. Gabay C. 2006. Interleuki-6 and chronic inflammation. Arthritis Research \& Therapy; $8($ suppl 2):S3.

6. Ohl K, Tenbrock K. 2011. Inflammatory Cytokines in Systemic Lupus Erythematosus. Journal of Biomedicine and Biotechnology;1-14.

7. Chun HY, Chung JW, Kim HA, Yun JM, Jeon JY, Ye YM, Kim SH, Park HS, Suh CH. 2007. Cytokine IL-6 and IL-10 as Biomarkers in Systemic Lupus Erythematosus. J Clin Immunol;27:416-466.

8. Jone SA, Frase DJ, Fielding CA, Jones GW. 2014. Interleukine-6 in renal diseas and therapy. Nephrol Dial Transplant;10:1-10.

9. Yael N-A, Daniel B, Galina P, Anat S, Stefan R-J, Eithan G, Jonathan HA. 2008. IL-6/IL-6R Axis Plays a Critical Role in Acute Kidney Injury. J Am Soc Nephrol;19:1106-1115.

10. Niels CR, Thomas AN, Ren-Feng G, Kurt DB, Ines JL, Vidya S, John DL, Peter AW. 2003. Protective Effect of IL-6 Blockade in Sepsis Are Linked to Reduced C5a Receptor Expression. J Immunol;170:503-507.

11. Allesandro C, Piera VP, Rossana F, Paola G, Annalisa S, Andrea ES, Riccardo M, Elisabetta C, Davine A, Iolanda R, Antonio M. 2014. Interleukin 1, Interleukin 6, Interleukin 10, and Tumor Necrosis Factor $\alpha$ in Active and Quiescent Systemic Lupus Erythemathosus. Journal of Investigative Medicine;62(5):825-829.

12. Alaa AS, Abdalla MK, Mona AE, Farg BE, Sherief RE. 2005. Proinflamatory Cytokines (TNF alpha and IL-6) in Egytptian SLE Patient With Lupus Nephritis Is it correlated with diseases activity? Eur J Gen Med;2(4);153-158.
13. Colado S, Macedo G, Miglioranza A, Frizon A, Perugini S, Batisti L, Vissoci R, Kaminami M, Delicito A, Mayumi VI, Tomimura C, Dichi MM. 2017. Systemic Lupus Erithematosus and Severity of Illness are Asscociated With T Herlep and 17 Cytokines Profile Together With a Lowered IL-4 Production. Lupus Sci Med;10:459.

14. Sahar M, Abdel G, Nillie E, Mohamed EE. 2015, The role of serum IL-17 and IL- 6 as bomarkers of diseases activity and predictors of remission in patients with lupus nephritis. Journal of cytokine;05(007):1043-1050.

15. Belinda TL, Faheemuddin AA, Lee H, Federico JT, Chung-Shiuan C, Yanxi L, Kamal S, Nade R, Vecihi B, Eric ES, Jiang H, Jiang C. 2015. Association of C-reactive protein, tumor necrosis factor-alpha, and interleukin-6 with chronic kidney diseases. BMC Nephrology;16:77.

16. Jayanta G, Nandita M, Peter AK, Joy D, Maria RW, Muredac R, Vallabh OS, Vaidyanthapura SB, Nicolas JG, Matthias G, Brian GP, Harlod IF, John WK, Marshall MJ, Dominic SR. 2012. Association between albuminuria, kidney function, and inflammatory biomarker profile in CKD in CRIC. Clin J Am Soc Nephrol;7:1938-1946.

17. Alfons S-M, Clara C-C, Naiara V-C, Irene A-P, Natalia R-T, Elias JE, Elena O-R. 2017. Value of urinary level of interleukin-6, epidhermal growt factor, monocyte chemoattractant protein type 1 and transforming growth factor $\beta 1$ in predicting the extent of fibrosis lesion in kidney biopsies of patients with IgA Nephrophaty. Nefrologia;37(5):531-538.

18. Dima A, Jurcut C, Balanescu P, Balanescu E, Badea C, Caraiola S, Miler I, Ramba D, Ionescu R, Baicus C, Dan GA, Mircescu G. 2016. Clinical significance of serum and urinary interleukin-6 in systemic lupus erithematosus patient. The Egyptian Rheumatologist;39:1-6.

19. Harrera-Esparza R, Barbosa-Cisneros O, Villalobos-Hurtado R, AvalosDiaz E. 1998. Renal Expression of IL-6 and TGF $\alpha$ genes in lupus nephritis. Lupus;7:154-158.

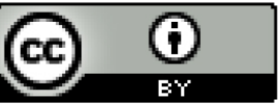

This work is licensed under a Creative Commons Attribution 4.0 International License. 